\title{
Implications of patient-borne costs associated with pediatric neurosurgical care in eastern Africa
}

\author{
Jonathan Awori, MFA, ${ }^{1,2}$ Jennifer Strahle, MD, ${ }^{1}$ Humphrey Okechi, MBChB, ${ }^{3}$ and \\ Matthew C. Davis, MD

\begin{abstract}
1Department of Neurosurgery and ${ }^{2}$ School of Public Health, University of Michigan, Ann Arbor, Michigan; ${ }^{3}$ Department of Surgery, Division of Neurosurgery, AIC Kijabe Hospital, Kijabe, Kenya; and ${ }^{4}$ Department of Neurosurgery, University of Alabama at Birmingham, Alabama
\end{abstract}

OBJECTIVE Pediatric neurosurgery can be highly cost-effective even in the developing world, but delivery of these services is hampered by resource limitations at the levels of both health care infrastructure and individual patients. Few studies have evaluated costs borne by neurosurgical patients in the developing world and their potential implications for efficient and effective delivery of care in this population.

METHODS The families of 40 pediatric neurosurgery patients were surveyed in February 2015 at the AIC Kijabe Hospital in Kijabe, Kenya. Costs associated with obtaining inpatient care were assessed.

RESULTS Patient families were charged an average of US $\$ 539.44$ for neurosurgical services, representing $132 \%$ of their annual income. Indirect expenses (transport, food and lodging, lost wages) constituted US \$79.37, representing $14.7 \%$ of the overall cost and $19.5 \%$ of their annual income.

CONCLUSIONS Expansion of pediatric neurosurgical services throughout the developing world necessitates increased attention to seemingly insignificant expenses that are absorbed by patients and their families. Even when all direct costs are covered at the institutional or national level, without additional assistance, some patients may be too poor to obtain even "free" neurosurgical care.

http://thejns.org/doi/abs/10.3171/2015.11.PEDS15445

KEY WORDS pediatric neurosurgery; global health; socioeconomic

$\mathrm{P}$ EDIATRIC neurosurgical care is locally unavailable to the majority of patients throughout the world, and the gap between capacity and need for neurosurgical services remains wide. ${ }^{51}$ There have been multiple efforts to address this gap, with one study demonstrating that pediatric hydrocephalus can be treated cost-effectively in sub-Saharan Africa via endoscopic third ventriculostomy (ETV), albeit with institution-specific expertise. ${ }^{53}$

Kenya has a population of over 44 million, with $55 \%$ under the age of 18 years. A reported $43.4 \%$ of the population earns less than the equivalent of US $\$ 1.25$ per day, falling under the international poverty line (http://data.worldbank. org/country/kenya). The gap between capacity and need for pediatric neurosurgical care in Kenya remains great. Seventeen Kenyan neurosurgeons provide both adult and pediatric care for the entire country; 15 of these surgeons practice in the capital, Nairobi, and have varying levels of pediatric subspecialty training. Spina bifida and hydrocephalus are the most prevalent pediatric neurosurgical conditions in Kenya, and the most common cause of hydrocephalus in this population is spina bifida. Although inadequate folate intake is associated with neural tube defects, maternal exposure to fumonisin, a mycotoxin that contaminates corn, may be a more important factor in the etiology of spina bifida in Kenya (A.L. Albright, personal communication, 2015). ${ }^{32}$

In most developing countries, subspecialty surgical services are highly centralized, generally available only in large cities, and frequently available only to those patients who can pay for them. ${ }^{29,56}$ This is particularly true in neurosurgery, which requires well-developed anesthesia, critical care, radiologic, and oncological programs for appropriate patient care. ${ }^{7}$ Single departments or even individual pediatric neurosurgeons may, in some cases, provide care for a population of millions, in catchment areas spanning thousands of square miles. ${ }^{21,22}$ While short-term visiting surgical teams may assist in closing a portion of this gap, infrequent follow-up and low priority of training local pro-

ABBREVIATIONS CPC = choroid plexus coagulation; ETV = endoscopic third ventriculostomy; EVD = external ventricular drain; NHIF = National Health Insurance Fund; $\mathrm{VP}=$ ventriculoperitoneal. 
viders has led to criticism of providing care through this model. $., 23,44$

Local neurosurgeons and national ministries of health as well as international neurosurgical groups working to expand area subspecialty capacity are nearly always mindful of these issues. ${ }^{2,26,30,52}$ However, consideration of resource limitations tends to focus on the health care infrastructure, and few studies address costs that are assumed to be insignificant and are expected to be absorbed by patients and families. $5,7,25,27,40$

Even if national health insurance programs or philanthropic groups cover the cost of outpatient diagnosis and follow-up, surgical expenses, and inpatient care, providing subspecialty care to the destitute still poses unique challenges in developing countries. Some patients are, quite simply, too poor to obtain "free" subspecialty care. Longdistance travel, time off from work or other obligations, and even food and lodging can all exceed the resources each family is able to bring to bear. ${ }^{16,18}$ Overcoming these hurdles is essential, as undue financial burden results in delayed diagnosis and referral, poor postoperative follow-up, and difficulty in identifying and managing late postoperative complications..$^{27}$ Ultimately, the societal cost of failing to treat these patients-through lost productivity, preventable morbidity and mortality, and higher long-term medical costs resulting from delayed access to care-is typically higher than these easily overlooked but prohibitive patient-borne expenses. ${ }^{8}, 17,45$ Here, we evaluate the costs associated with obtaining pediatric neurosurgical care at AIC Kijabe Hospital, a mission hospital in Kijabe, Kenya, and consider the impact on care delivery in this setting.

\section{Methods \\ Patient Selection}

Patients were selected based on having undergone a pediatric neurosurgical operation and inpatient stay at AIC Kijabe Hospital over a 4-week period in early 2015. All patients who were discharged from the hospital during the study period were eligible for inclusion in this study. $\mathrm{Pa}-$ tients were excluded if their stay extended beyond the study period, due to inability to obtain complete hospital cost data. Follow-up ended at hospital discharge. Local doctors, nurses, and staff helped to identify candidates who met the inclusion criteria. To confirm that this sampling was representative of the spectrum of procedures performed at AIC Kijabe Hospital, we compared procedure data with the 2014 annual report of pediatric neurosurgical operations performed at AIC Kijabe Hospital (Table 1). The majority of patient families were interviewed at follow-up visits after the patients were discharged from the hospital; however, a few families were interviewed shortly prior to discharge as detailed below.

\section{Data Collection}

Over the course of 4 weeks in February 2015, one member of the research team interviewed mothers of pediatric neurosurgical patients at AIC Kijabe Hospital and at a satellite mobile clinic in Thika, Kenya. Of 40 participants, 8 were interviewed at the time of hospital discharge, while the remaining patients were interviewed at the first follow-
TABLE 1. Procedures performed on patients included in the study, all patients during the study period, and all procedures performed at Kijabe Hospital during 2014*

\begin{tabular}{lccc}
\hline \multicolumn{1}{c}{ Procedure } & $\begin{array}{c}\text { Included } \\
\text { Pts }\end{array}$ & $\begin{array}{c}\text { Pts in Study } \\
\text { Period }\end{array}$ & $\begin{array}{c}\text { Procedures } \\
\text { in 2014 }\end{array}$ \\
\hline VP shunt insertion & $13(33)$ & $15(29)$ & $384(34)$ \\
\hline Spinal dysraphism repair & $12(30)$ & $12(23)$ & $229(21)$ \\
\hline ETVICPC & $4(10)$ & $7(13)$ & $126(11)$ \\
\hline Shunt revisions & $2(5)$ & $4(8)$ & $86(8)$ \\
\hline EVD placement/removal & $0(0)$ & $2(4)$ & $72(6)$ \\
\hline Tumor resection & $0(0)$ & $1(2)$ & $83(7)$ \\
\hline Tethered cord release & $6(15)$ & $6(12)$ & $26(2)$ \\
\hline Wound revision & $1(3)$ & $3(6)$ & $60(5)$ \\
\hline Other & $2(5)$ & $2(4)$ & $51(5)$ \\
\hline Total & $40(100)$ & $52(100)$ & $1117(100)$ \\
\hline
\end{tabular}

Pts = patients.

* Values are number (\%).

up clinic visit, within 1 month of discharge. Participants were queried principally on costs that were not reflected in the medical billing record. Data collected included distance of travel, transportation costs, food and lodging for accompanying family members, lost wages of parents and other family members, length of time off work, annual family income, and occupation. (All expenses are reported in US dollars.) All mothers were asked the same series of questions using a standardized questionnaire. Lost wages were verified with reference to current Kenya Ministry of Labor minimum wage schedules (http://labour.go.ke/ downloads/Minimum\%20Wages.pdf). Reported public transport costs were compared with the published fares and schedules of the Easy Coach Bus Company, the typically used long-distance bus company in Kenya (http:// www.easycoach.co.ke/nairobi-to-upcountry.html). Guest lodging costs were verified with the AIC Kijabe Hospital Guesthouse fixed single rate of $\$ 5$ per night, and reported food costs were validated based on the cost of an average meal at the hospital cafeteria of $\$ 1$. One-way ANOVA was used to compare seasonal variation in total hospital billing costs for patients admitted during the months of JanuaryMarch, April-June, July-September, and October-December. Contingency analysis of admission diagnosis by season was performed for the top 7 admission diagnoses (i.e., those applied in more than 10 cases).

Following the completion of parent interviews, the medical record was retrospectively reviewed for costs incurred during the hospital stay. These areas included cost of radiology, laboratory tests, medications, medical supplies, neurosurgical procedures performed, and overall billing charges for hospital services. If the patients held any insurance-most commonly the government-run National Health Insurance Fund (NHIF) - the contribution was additionally noted. With insurance information factored in, the actual amount the patients were responsible for was calculated. At AIC Kijabe Hospital, unlike in the United States, hospital billing charges are fixed and are not altered by insurance status or patient income. As the 
primary goal of this study was to evaluate the financial burden of obtaining neurosurgical care on patients and families, hospital billing charges were used to determine the direct expenses of obtaining care, as this represents the amount patients are expected to pay for services rendered. This information was integrated with the parent interview data to obtain a comprehensive understanding of the patient cost burden in obtaining pediatric neurosurgical care at AIC Kijabe Hospital. The medical record was further reviewed for the above costs incurred during the hospital stay of all patients treated at AIC Kijabe Hospital in 2014. The matched-pairs t-test was used to compare hospital billing charges for study patients with all patients treated at AIC Kijabe Hospital in 2014.

This study was reviewed by the medical science institutional review board of the University of Michigan. Local ethical research approval was obtained from the institutional review board of AIC Kijabe Hospital. Informed consent was obtained from all participants.

\section{Results}

A total of 40 patients discharged from AIC Kijabe Hospital following a pediatric neurosurgery procedure during a 4-week period in early 2015 met inclusion criteria, and their families agreed to participate in the study. An additional 12 neurosurgical procedures were performed during this same period, but in those cases the patients were deemed ineligible for inclusion because either their inpatient stay extended beyond the study period or missing financial records from their medical file precluded a complete review.

\section{Demographics}

Case procedures included 13 ventriculoperitoneal (VP) shunt insertions, 12 myelomeningocele repairs, 6 tethered cord releases, 4 ETVs with choroid plexus coagulation (ETV/CPC), 2 shunt revisions, 1 endoscopic cyst fenestration, 1 occipital encephalocele repair, and 1 lumbar CSF leak repair. The breakdown of procedures performed is presented in Fig. 1. A total of 998 patients were admitted to AIC Kijabe Hospital in 2014; 956 of these patients underwent at least 1 neurosurgical procedure, and a total of 1117 procedures were performed. One hundred sixty-one procedures were carried out in patients who underwent more than 1 procedure during their stay. These included 36 additional external ventricular drain (EVD) placement or removal procedures, $55 \mathrm{ETV} / \mathrm{CPCs}, 22 \mathrm{VP}$ shunt placements or revisions, 6 myelomeningocele repairs, 7 tumor resections, and 9 wound revisions. The distribution of cases included in this study was not significantly different from that of all 52 surgical procedures performed during the study period $(\mathrm{p}=0.5)$ or all of the procedures performed in $2014(\mathrm{p}=0.54)$. A comparison of the study period procedures and the annual breakdown of operations performed at AIC Kijabe Hospital demonstrates that the sample studied is representative of the typical operative load (Table 1).

One-way ANOVA was used to compare seasonal variation in total hospital billing cost for 2014. No significant difference was found between these groups $(p=0.23)$. There was, however, a statistically significant difference in frequency of the top 7 admission diagnoses by season (Pearson correlation coefficient 39.7, p < 0.01), displayed in Fig. 2.

The 40 patients who were included in the study originated from 22 separate villages and traveled a mean distance of 138.15 miles to reach AIC Kijabe Hospital. A cartographic representation of distance traveled to obtain care is shown in Fig. 3. The mean duration of hospital stay was 11.0 days (range 2-60 days, median 7 days). Family

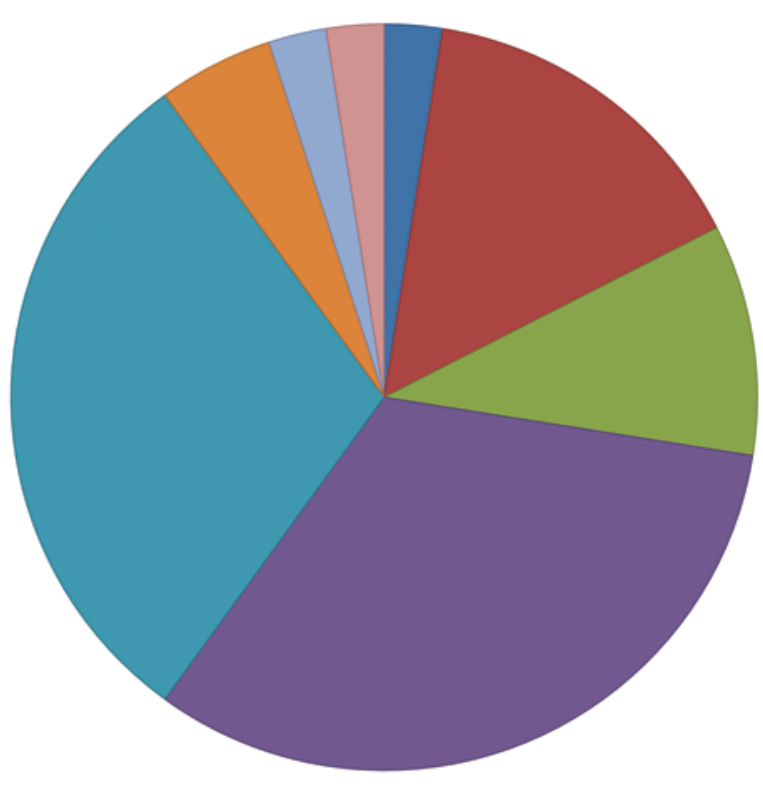

Endoscopic cyst fenestration

Tethered cord release

ETV/CPC

Ventriculoperitoneal shunt

Myelomenigocele repair

Shunt revision

$\square$ Occipital encephalocele resection

\section{$\square$ CSF leak repair}

FIG. 1. Pie chart showing the breakdown of the procedures performed in the 40 patients included in the study. Figure is available in color online only. 


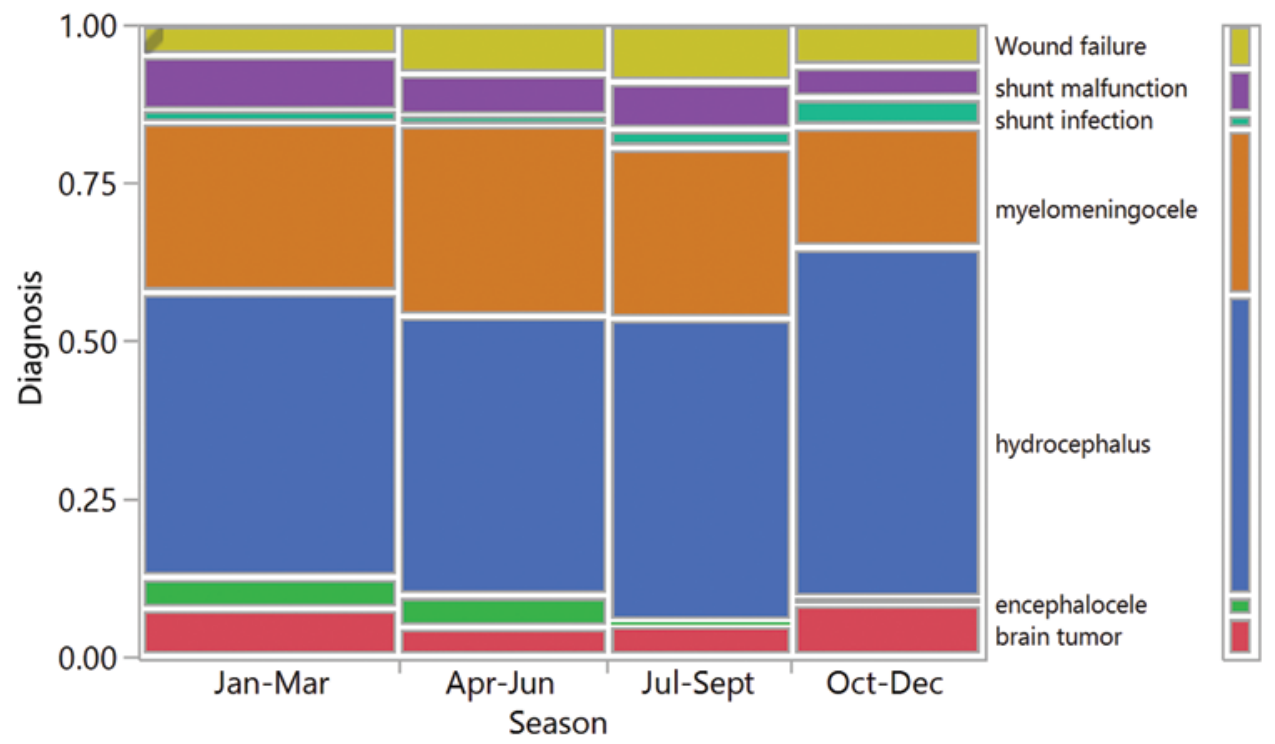

FIG. 2. Mosaic plot of the top 7 primary admission diagnoses as a function of season during 2014. Figure is available in color online only.

income was lost for a mean of 4.48 days (range 0-60 days, median 2 days). Family demographic characteristics and occupations are presented in Table 2.

\section{Patient and Family Expenses}

The mean annual family income of the study patients

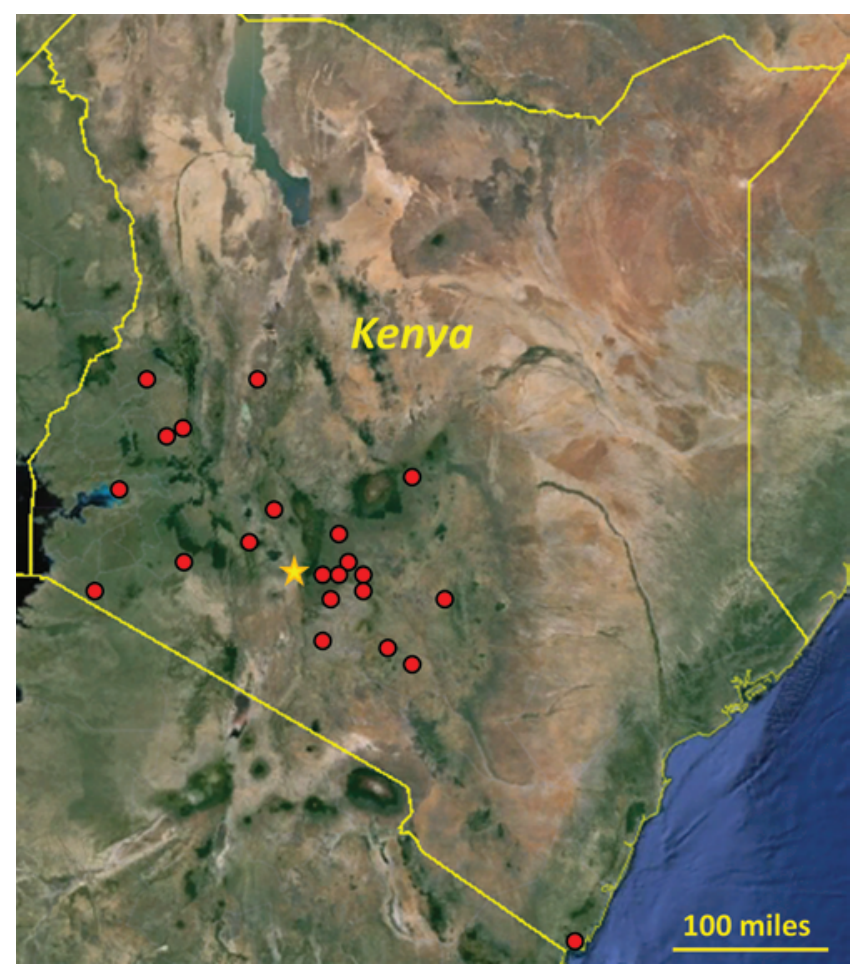

FIG. 3. Topographic map of Kenya showing the distance traveled by patients to obtain care. Patient homes and AIC Kijabe Hospital are represented by red circles and the yellow star, respectively. Figure is available in color online only. was $\$ 407.92$ (range $\$ 0-\$ 3913$, median \$212) while the mean overall cost of obtaining pediatric neurosurgical care was $\$ 539.44$, representing $132 \%$ of the average annual family income. Indirect expenses (transport, family food and lodging, lost wages) averaged \$79.37, accounting for $14.7 \%$ of the overall cost and $19.5 \%$ of the mean annual family income. Transportation costs ranged from $\$ 0$ to $\$ 108.70$, with a median of $\$ 34.17$. Bus travel was the most common means of transportation. Values reported during family interviews were consistent with typical transportation cost in the region. One-way bus fare from each patient's home to Kijabe ranged from $\$ 9.50$ to $\$ 15.00$ based on the originating site. Reported lost wages were consistent with current Kenya Ministry of Labor minimum wage schedules for each profession (Table 3). Forty percent of the patients in the study were able to obtain national health insurance while $29 \%$ of all patients treated in 2014 obtained health insurance.

While patients are billed for the actual cost of their care, most are unable to remit payment in full. In 2014, actual hospital reimbursement was $27.9 \%$ of the total billing charges, with patients paying $14.3 \%$ of the hospital bill and the NHIF paying $13.6 \%$ of the total charges. Thus, in 2014, BethanyKids ultimately covered $72 \%$ of the hospital costs not covered by patient or the NHIF.

Of note, these findings do not account for expenses incurred in obtaining initial diagnostic imaging and primary care physician evaluation. The majority of patients presented to AIC Kijabe Hospital with prior imaging, and we were unable to collect data on the cost per patient of outside imaging. For reference, the typical cost for CT scanning in Kenya ranges from $\$ 58.80$ to $\$ 73.50$, radiography $\$ 18.40$, head ultrasound $\$ 10.90$, and brain MRI $\$ 1862$ (H.O., personal communication). Patients on average are seen 3-4 times for postoperative follow-up in a series of mobile clinics, with minimal associated transportation cost or lost wages, and are not charged for these visits. A 
TABLE 2. Family demographic characteristics and the impact of obtaining care*

\begin{tabular}{|c|c|}
\hline Variable & Value \\
\hline \multicolumn{2}{|l|}{ Burden } \\
\hline \multicolumn{2}{|l|}{ Travel distance (miles) } \\
\hline Range & $30-600$ \\
\hline Mean & 138.15 \\
\hline Median & 116 \\
\hline \multicolumn{2}{|l|}{ LOS (days) } \\
\hline Range & $2-60$ \\
\hline Mean & 11.0 \\
\hline Median & 7 \\
\hline \multicolumn{2}{|l|}{ Time off work (days) } \\
\hline Range & $0-60$ \\
\hline Mean & 4.48 \\
\hline Median & 2 \\
\hline \multicolumn{2}{|l|}{ Family occupation } \\
\hline \multicolumn{2}{|l|}{ Day labor } \\
\hline No. of families & 18 \\
\hline Mean annual family income (\$) & 280.87 \\
\hline \multicolumn{2}{|l|}{ Farming } \\
\hline No. of families & 8 \\
\hline Mean annual family income (\$) & 224.40 \\
\hline \multicolumn{2}{|l|}{ Business } \\
\hline No. of families & 9 \\
\hline Mean annual family income (\$) & 1126.36 \\
\hline \multicolumn{2}{|l|}{ Other* } \\
\hline No. of families & 5 \\
\hline Mean annual family income (\$) & 76.87 \\
\hline
\end{tabular}

LOS = length of hospital stay.

* Includes the following occupations: secretary, herbalist, hairdresser, handiworker, teacher.

breakdown of costs associated with obtaining care is presented in Table 4. The matched-pairs t-test demonstrated that mean hospital billing charges for the patients included in our study were not significantly different from charges for all patients treated at AIC Kijabe Hospital in 2014 ( $\mathrm{p}=$ 0.67). A graphical representation of the cost of obtaining care as a function of annual income is presented in Fig. 4.

\section{Discussion}

\section{Local Research Context}

AIC Kijabe Hospital is a nonprofit mission hospital located in Kijabe, Kenya. Kijabe is located in a rural area 50 miles northwest of Nairobi, within the Rift Valley escarpment. The hospital has been able to expand its offerings through a series of key partnerships, most notably with BethanyKids, a Christian organization committed to expanding access to pediatric surgical and pediatric neurosurgical care in sub-Saharan Africa.

AIC Kijabe Hospital is currently the only site in Kenya dedicated to pediatric neurosurgical care, and patients arrive at the hospital from as far as Kisumu, in the west, to
TABLE 3. Minimum wage schedules by profession, Kenya Ministry of Labor 2015

\begin{tabular}{lcl}
\hline \multirow{2}{*}{ Occupation } & \multicolumn{2}{c}{ Wages (US \$) } \\
\cline { 2 - 3 } & Month & Day \\
\hline Unskilled employee & 55 & 2 \\
\hline Domestic help or cook & 62 & 2.3 \\
\hline Stockman, herdsman, watchman & 63 & 2.6 \\
\hline Senior foreman & 64 & 2.7 \\
\hline Farm artisan & 65 & 2.8 \\
\hline Tractor driver & 70 & 3 \\
\hline Combine harvester driver & 76 & 3.2 \\
\hline Lorry or car driver & 79 & 3.3 \\
\hline Farm foreman & 98 & 4 \\
\hline Farm clerk & 98 & 4 \\
\hline
\end{tabular}

the coastal town of Mombasa, in the southeast, encompassing a catchment area of over 200,000 square miles. The hospital is a 280 -bed facility with a staff of 700 . The hospital articulates its mission as providing high-quality medical care to the "poor and vulnerable." Having this target population means that a majority of the patients either cannot afford the care or can pay at most only a portion of the cost of their care.

The pediatric neurosurgical service at AIC Kijabe Hospital currently carries out operations on approximately 600 children per year, expanding local neurosurgical capacity through residency and fellowship training. In prior years, including 2014, the operating load was significantly higher, but it decreased with the founding neurosurgeon's departure from the program in early 2015. The full range of pediatric neurosurgical disorders continues to be treated.

\section{Global Subspecialty Surgery}

While many disciplines within global health have a long history of academic investigation, rigorous and systematic evaluation of subspecialty surgery in the developing world remains uncommon. Indeed, surgical intervention has only recently been broadly accepted as playing an essential role in global health, $, 211,30$ and subspecialty surgical care is not readily available in much of the world. ${ }^{43,50}$ Thus, evaluation of the unique obstacles to providing high-quality, high-complexity neurosurgical care in a lowresource context has been limited. $15,19,24,25,31,34,38,53,54$

Although AIC Kijabe Hospital commits to serving patients regardless of their ability to pay, significant challenges remain. Previous studies have indirectly estimated the patient cost burden with such methods as extrapolation from national gross domestic product and approximations of transport costs. ${ }^{33,46}$ In this study, we attempted to garner this information directly through interviews and, in the process, uncovered other hidden costs.

\section{Cultural Factors Influencing Care Delivery}

Financial burden is the predominant factor in medical decision making for many patients. However, trust in the local health care system, adoption of a Western model of 
TABLE 4. Breakdown of pediatric neurosurgical costs*

\begin{tabular}{|c|c|c|}
\hline Cost & Study Pts, No. $=40$ & $\begin{array}{c}\text { All } 2014 \text { Admissions, } \\
\text { No. }=998\end{array}$ \\
\hline \multicolumn{3}{|l|}{ Indirect } \\
\hline $\begin{array}{l}\text { Travel to \& } \\
\quad \text { from Tx site }\end{array}$ & $34.20(0-108.70)$ & - \\
\hline $\begin{array}{l}\text { Food \& lodg- } \\
\text { ing } t\end{array}$ & $7.20(0-65.22)$ & - \\
\hline Lost wages & $38.00(0-543.00)$ & - \\
\hline \multicolumn{3}{|l|}{ Direct medical } \\
\hline Radiology $\ddagger$ & $13.50(0-24.00)$ & $9.40(0-120.70)$ \\
\hline $\begin{array}{l}\text { Laboratory } \\
\text { tests }\end{array}$ & $31.30(0-149.40)$ & $45.60(0-1116.50)$ \\
\hline Medications & $45.80(0-1115.00)$ & $53.10(0-4747.90)$ \\
\hline Supplies & $35.10(0-73.40)$ & $28.60(0-949.70)$ \\
\hline $\begin{array}{l}\text { Inpatient } \\
\text { hospital§ }\end{array}$ & $426.30(149.21-755.27)$ & $411.50(6.20-4896.50)$ \\
\hline $\begin{array}{l}\text { Insurance pay- } \\
\text { mentף }\end{array}$ & $-83.10(0$ to -757.00$)$ & -75.20 (0 to -2799.00$)$ \\
\hline Total direct to $\mathrm{pt}^{* *}$ & $468.90(82-1321.00)$ & $473(0-8979.70)$ \\
\hline $\begin{array}{l}\text { Total direct \& } \\
\text { indirect to pt }\end{array}$ & $548.30(110.00-1469.00)$ & - \\
\hline \multicolumn{3}{|c|}{$\begin{array}{l}\text { Tx = treatment. } \\
\text { * Values are mean US } \$ \text { (range US \$). } \\
\dagger \text { Only } 13 \text { study patients incurred additional costs for food and lodging in } \\
\text { Kijabe. Most mothers stayed with the patient during their stay, and food was } \\
\text { provided in addition to lodging. Several families living close to Kijabe walked, } \\
\text { biked, or obtained private transportation home each day, without incurring } \\
\text { additional costs for food or lodging. } \\
\ddagger \text { Fourteen study patients underwent imaging during their hospitalization; the } \\
\text { cost of previous outpatient diagnostic imaging was unavailable. } \\
\S \text { Includes cost of hospital stay, procedure, and physician payment. } \\
\text { † A total of } 16 \text { study patients ( } 40 \% \text { ) possessed national health insurance; } 29 \% \\
\text { of all patients treated in } 2014 \text { possessed insurance coverage. } \\
* \text { Represents the total cost after deduction of insurance payment. }\end{array}$} \\
\hline
\end{tabular}

illness and medicine, and attitudes toward pediatric neurological disability all have dramatic local variability and varying influence on all aspects of care. , $^{6,72}$

In this study population, we did receive occasional reports from participants of negative attitudes held by relatives, particularly toward patients with hydrocephalus and spina bifida variants. While not directly solicited, revelations of family attitudes and beliefs came up naturally during the interview process. These discussions proved insightful into cultural obstacles that directly exacerbate the financial burden. In some cases, families had strongly advised the parents to refrain from spending money on disabled or "damaged" children and were reluctant to financially support mothers who continued to pursue aggressive treatment. In other cases, the father's family members interpreted the distorted shape of the skull in hydrocephalus as an indictment of the mother, citing a curse or deficiency. Some mothers reported that their husbands had left them after their children developed hydrocephalus. These mothers, already dependent on their families for support, thus suffered a financially devastating double hit-high medical bills associated with neurosurgical care coupled with the cutoff in family support. Such stigmatization has appeared in other efforts in Africa. ${ }^{35}$ In certain communities in Uganda, there is an erroneous association between the mother's use of contraceptives prior to pregnancy and the subsequent development of birth defects including hydrocephalus and spina bifida. ${ }^{1,3,4,49}$ It should be emphasized that the reports we did receive arose spontaneously and were not in direct response to a targeted interview question, as the focus of our study was traditional direct and indirect physical costs. However, given the revelation of such cultural influences, future survey analyses would benefit from the inclusion of questions that explore potential financial effects of disease stigmatization.

While family attitudes and local contextual understanding of neurological disease is well studied in the sociological and anthropological literature, ${ }^{36,39,42,44,47}$ these topics rarely appear in the neurosurgical literature. This is troubling, as the complex interplay of family dynamics, local socioeconomic status, family support structure, and access to fungible resources/monetary currency all influence the likelihood of patients to present early for diagnosis, comply with treatment recommendations, and attend scheduled follow-up visits. ${ }^{37}$ We seek to encourage a broader view of neurosurgical care by providing the full context of costs, so that interventions are not underestimated, and cultural considerations that may affect care are not overlooked.

\section{Burden and Implications of Transportation Costs}

Patients must first be able to afford the cost of transportation, which can be prohibitive given that many must travel long distances, and transportation costs form a significant percentage of their annual income. ${ }^{13,20,48}$ One attempt to address the issue of transportation cost and to improve follow-up rates has been to encourage patients to visit local mobile clinics for follow-up. In addition, AIC Kijabe Hospital has an informal payback system for any portions of the bill that remain outstanding following discharge. At each follow-up visit, a social worker asks the mother to clear a portion of her outstanding bill. This arrangement, while demonstrating flexibility on the part of AIC Kijabe Hospital, raises the question of whether pursuing followup care may be affected by parental concern that they will be asked to pay a portion of the bill, for which they may not be prepared. This arrangement may make parents less likely to pursue follow-up care.

While it is possible that concerns about being asked for payment could be a deterrent, the social workers are trained to ask about these payments in a direct but nonconfrontational way. They are also uniquely equipped to work with patients' families to solve problems related to further payment in the context of their financial limitations. In $2014,80 \%$ of families presented for at least 1 postoperative follow-up visit.

As the majority of patients' mothers were interviewed in the context of follow-up visits, our figures are a conservative estimate of the true cost burden given that a number of patient families were likely limited from attending even mobile clinic appointments due to financial constraints.

\section{Opportunity Costs in a Low-Resource Environment}

Aside from tangible costs, such as transport and lost 


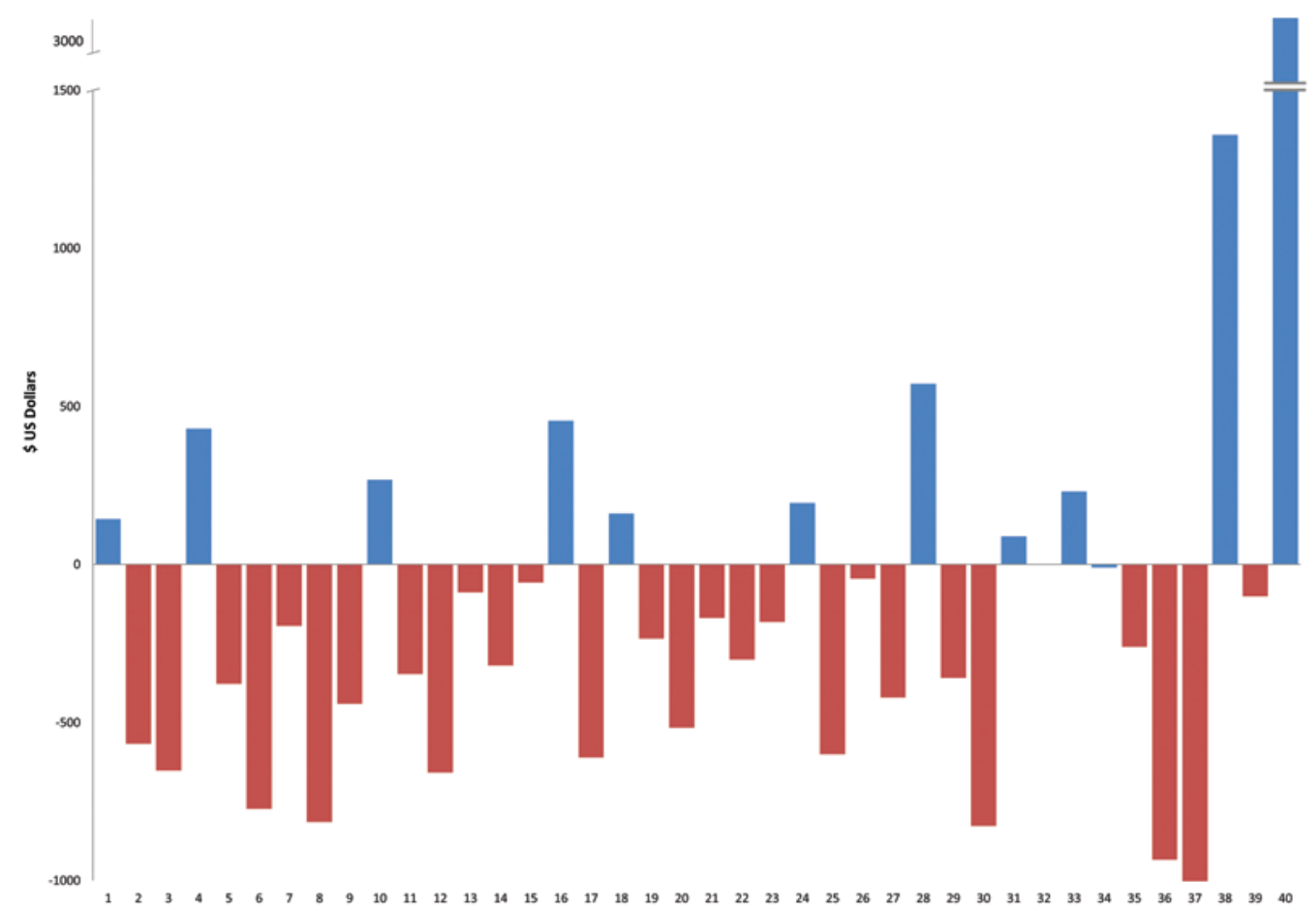

FIG. 4. Graph showing individual burden represented by the total cost of obtaining pediatric neurosurgical care in US dollars for each patient, subtracted from the family income for that patient. Patients for whom the cost of care exceeded the annual income are represented in red. Figure is available in color online only.

wages, there is also the high opportunity cost of lost time. ${ }^{14,41,55}$ Lost family income poorly reflects the value of time spent in obtaining neurosurgical care. Many family members, and nearly all mothers in this study, hold occupations with limited or no monthly reimbursement. The opportunity cost of time spent is less easily quantified for a homemaker or subsistence farmer than for an individual with a wage-based occupation. The model of admission at AIC Kijabe Hospital means that mothers stay in the ward with their children for their entire stay. The opportunity cost includes being unavailable to sell produce at the market, perform a day laborer task, or pursue any other means of informal income. There is other familial impact as well; siblings cannot be attended to, and their success or failure in school can often hinge on one national examination grade. The mother's unavailability to guide this process can have long-term financial impact for the family.

Thus the high opportunity cost of lost time cannot be overstated. ${ }^{10,28}$ For many patients with limited resources, lost time alone represents an insurmountable financial burden. Even if every medical expense is absorbed by an institution such as AIC Kijabe Hospital, some families are too poor to absorb the associated costs. At the least, these limitations will delay timely diagnosis and treatment, with resultant negative impact on patient outcomes.$^{40}$ Providers must be mindful of the additional resources necessary to identify the patients at highest risk. These issues are well known by providers on the ground but are rarely discussed in the literature.

Although our results underestimate the true burden of having a child requiring neurosurgical intervention, family income remains a valuable metric, as hospital bills demand hard currency. This places bill repayment even further out of reach for many, despite gainful employment.

\section{Ongoing Efforts to Manage Costs}

Despite these challenges, AIC Kijabe Hospital is working hard to overcome patient barriers to care. Upon admission, patients are actively recruited to the NHIF. This national insurance program pays a flat daily rate for inpatient care, which significantly reduces the cost of stay. While the surgical procedures account for the bulk of the cost, the real price is often the delay of care. Patients with myelomeningocele, who should be brought to the hospital within 72 hours after birth, are often not brought for care until they are as old as 9 months, leading to detrimental neurological sequelae. When mothers are asked what takes them so long to bring their children to the hospital, the answer is as simple as it is unfortunate: cost.

In spite of all of these challenges, providing pediatric neurosurgical care in this center and similar programs remains an important intervention. The natural history of both spina bifida and hydrocephalus leads to significant morbidity and mortality, exponentially increasing the financial impact on families and the health care system. The cost-effectiveness of ETV/CPC for pediatric hydrocephalus in neighboring Uganda has been demonstrated. ${ }^{53}$ However, cost-effectiveness discussions in the developing world typically revolve around resource limitations at the health care infrastructure level. ${ }^{8}$ Few studies have evalu- 
ated costs borne by neurosurgical patients and the potential implications for efficient and effective delivery of care.

For any pediatric neurosurgeons seeking, then, to provide neurosurgical care in Kenya, it is advisable to factor in that the patient burden of cost accrues at more levels than may be apparent in the medical billing record. There are transportation costs, lost wages of mothers and other family members, and, in some cases, the financial and emotional isolation of cultural stigmatization around the deforming effects of these surgical conditions. While knowledge of these costs is unlikely to alter therapeutic recommendations per se, creative solutions must be sought to provide optimal care in this environment.

\section{Limitations and Future Studies}

This study is limited by its focus on a single cohort of patients at one hospital in Kenya. However, we anticipate that the experience of AIC Kijabe Hospital as a nonprofit institution operating in a low-resource setting, depending on a combination of partnerships, international volunteer physicians, and local contributions, is generalizable to similar institutions. However, since AIC Kijabe Hospital is a nonprofit facility with significant donor support, hospital billing charges may represent a "best possible case," which may not be generalizable to all other health systems in developing countries. We would argue, however, that our key finding is not the direct cost of health care, but rather the powerful and often unrecognized barriers of indirect and other hidden costs. This finding is likely widely generalizable.

Further limitations of the study include the unaccounted cost of outside imaging and follow-up costs after discharge from the hospital. Future cost analysis studies would do well to account for preoperative costs incurred at other locations prior to admission and costs associated with followup care. Additional studies are needed to determine whether compliance with medical management and consistency of follow-up can be impacted in a cost-effective manner by addressing patient-specific financial barriers to care.

\section{Conclusions}

Delivery of highly specialized surgical care in low-resource settings requires consideration of issues not faced in other medical disciplines and environments. Failing to address the financial burden absorbed by patients and families may lead to inefficient and incomplete care delivery. Expansion of neurosurgical services throughout the developing world necessitates increased attention to seemingly insignificant expenses absorbed by patients and their families.

\section{Acknowledgments}

We would like to thank Dr. A. Leland Albright for his assistance with study design, implementation, and manuscript review.

\section{References}

1. Agyei WK, Migadde M: Demographic and sociocultural factors influencing contraceptive use in Uganda. J Biosoc Sci 27:47-60, 1995

2. Alkire BC, Shrime MG, Dare AJ, Vincent JR, Meara JG:
Global economic consequences of selected surgical diseases: a modelling study. Lancet Glob Health 3 (Suppl 2):S21S27, 2015

3. Andi JR, Wamala R, Ocaya B, Kabagenyi A: Modern contraceptive use among women in Uganda: An analysis of trend and patterns (1995-2011). Etude Popul Afr 28:1009-1021, 2014

4. Asiimwe JB, Ndugga P, Mushomi J, Manyenye Ntozi JP: Factors associated with modern contraceptive use among young and older women in Uganda; a comparative analysis. BMC Public Health 14:926, 2014

5. Bagan M: The Foundation for International Education in Neurological Surgery. World Neurosurg 73:289, 2010

6. Barimah KB: Traditional healers as service providers in Ghana's National Health Insurance Scheme: the wrong way forward? Glob Public Health 8:202-208, 2013

7. Cadotte DW, Viswanathan A, Cadotte A, Bernstein M, Munie T, Freidberg SR: The consequence of delayed neurosurgical care at Tikur Anbessa Hospital, Addis Ababa, Ethiopia. World Neurosurg 73:270-275, 2010

8. Chao TE, Sharma K, Mandigo M, Hagander L, Resch SC, Weiser TG, et al: Cost-effectiveness of surgery and its policy implications for global health: a systematic review and analysis. Lancet Glob Health 2:e334-e345, 2014

9. Dupuis CC: Humanitarian missions in the third world: a polite dissent. Plast Reconstr Surg 113:433-435, 2004

10. Falkingham J: Poverty, out-of-pocket payments and access to health care: evidence from Tajikistan. Soc Sci Med 58:247258, 2004

11. Farmer PE, Kim JY: Surgery and global health: a view from beyond the OR. World J Surg 32:533-536, 2008

12. Folaranmi T: mHealth in Africa: challenges and opportunities. Perspect Public Health 134:14-15, 2014

13. Gakwaya A, Kigula-Mugambe JB, Kavuma A, Luwaga A, Fualal J, Jombwe J, et al: Cancer of the breast: 5-year survival in a tertiary hospital in Uganda. Br J Cancer 99:63-67, 2008

14. Garg CC, Karan AK: Reducing out-of-pocket expenditures to reduce poverty: a disaggregated analysis at rural-urban and state level in India. Health Policy Plan 24:116-128, 2009

15. Gathura E, Poenaru D, Bransford R, Albright AL: Outcomes of ventriculoperitoneal shunt insertion in Sub-Saharan Africa. J Neurosurg Pediatr 6:329-335, 2010

16. Grimes CE, Bowman KG, Dodgion CM, Lavy CBD: Systematic review of barriers to surgical care in low-income and middle-income countries. World J Surg 35:941-950, 2011

17. Grimes CE, Henry JA, Maraka J, Mkandawire NC, Cotton $\mathrm{M}$ : Cost-effectiveness of surgery in low- and middle-income countries: a systematic review. World J Surg 38:252-263, 2014

18. Gyedu A, Baah EG, Boakye G, Ohene-Yeboah M, Otupiri E, Stewart BT: Quality of referrals for elective surgery at a tertiary care hospital in a developing country: an opportunity for improving timely access to and cost-effectiveness of surgical care. Int J Surg 15:74-78, 2015

19. Hambrecht A, Duenas MJ, Hahn EJ, Aryan HE, Hughes SA, Waters D, et al: Strategic design for pediatric neurosurgery missions across the Western Hemisphere. Surg Neurol Int 4:62, 2013

20. Hamid SA, Ahsan SM, Begum A: Disease-specific impoverishment impact of out-of-pocket payments for health care: evidence from rural Bangladesh. Appl Health Econ Health Policy 12:421-433, 2014

21. El Khamlichi A: African neurosurgery: current situation, priorities, and needs. Neurosurgery 48:1344-1347, 2001

22. El Khamlichi A: Neurosurgery in Africa. Clin Neurosurg 52:214-217, 2005

23. Lang JM, Meixensberger J, Unterberg AW, Tecklenburg A, Krauss JK: Neurosurgical intensive care unit-essential for 
good outcomes in neurosurgery? Langenbecks Arch Surg 396:447-451, 2011

24. Levy ML, Duenas VJ, Hambrecht AC, Hahn EJ, Aryan HE, Jandial R: Pediatric neurosurgery outreach: sustainability appraisal of a targeted teaching model in Kiev, Ukraine. J Surg Educ 69:611-616, 2012

25. Mainthia R, Tye GW, Shapiro J, Doppenberg EMR, Ward JD: A model for neurosurgical humanitarian aid based on 12 years of medical trips to South and Central America. J Neurosurg Pediatr 4:4-9, 2009

26. Maki J, Qualls M, White B, Kleefield S, Crone R: Health impact assessment and short-term medical missions: a methods study to evaluate quality of care. BMC Health Serv Res 8:121, 2008

27. Mansouri A, Chan V, Njaramba V, Cadotte DW, Albright AL, Bernstein M: Sources of delayed provision of neurosurgical care in a rural Kenyan setting. Surg Neurol Int 6:32, 2015

28. McIntyre D, Thiede M, Dahlgren G, Whitehead M: What are the economic consequences for households of illness and of paying for health care in low- and middle-income country contexts? Soc Sci Med 62:858-865, 2006

29. Meara JG, Hagander L, Leather AJM: Surgery and global health: a Lancet Commission. Lancet 383:12-13, 2014

30. Meara JG, Leather AJM, Hagander L, Alkire BC, Alonso N, Ameh EA, et al: Global Surgery 2030: evidence and solutions for achieving health, welfare, and economic development. Lancet 386:569-624, 2015

31. Munyi N, Poenaru D, Bransford R, Albright L: Encephalocele - a single institution African experience. East Afr Med J 86:51-54, 2009

32. Mutiga SK, Hoffmann V, Harvey JW, Milgroom MG, Nelson RJ: Assessment of aflatoxin and fumonisin contamination of maize in western Kenya. Phytopath 105:1250-1261, 2015

33. Nguyen H, Ivers R, Jan S, Pham C: Cost of surgery and catastrophic expenditure in people admitted to hospital for injuries: estimates from a cohort study in Vietnam. Lancet $\mathbf{3 8 5}$ (Suppl 2):S50, 2015

34. Ochieng' N, Okechi H, Ferson S, Albright AL: Bacteria causing ventriculoperitoneal shunt infections in a Kenyan population. J Neurosurg Pediatr 15:150-155, 2015

35. Oyewole A, Adeloye A, Adeyokunnu AA: Psychosocial and cultural factors associated with the management of spina bifida cystica in Nigeria. Dev Med Child Neurol 27:498-503, 1985

36. Paschal AM, Ablah E, Wetta-Hall R, Molgaard CA, Liow K: Stigma and safe havens: a medical sociological perspective on African-American female epilepsy patients. Epilepsy Behav 7:106-115, 2005

37. Piquer J, Qureshi MM, Young PH, Dempsey RJ: Neurosurgery Education and Development program to treat hydrocephalus and to develop neurosurgery in Africa using mobile neuroendoscopic training. J Neurosurg Pediatr 15:552-559, 2015

38. Qureshi MM, Oluoch-Olunya D: History of neurosurgery in Kenya, East Africa. World Neurosurg 73:261-263, 2010

39. Rawlings CE III, Rossitch E Jr: The history of trephination in Africa with a discussion of its current status and continuing practice. Surg Neurol 41:507-513, 1994

40. Sedney CL, Siu J, Rosseau G, Dempsey R, Bernstein M: International neurosurgical volunteerism: a temporal, geographic, and thematic analysis of foundation for international education in neurological surgery volunteer reports. World Neurosurg 82:963-968, 2014

41. Shahrawat R, Rao KD: Insured yet vulnerable: out-of-pocket payments and India's poor. Health Policy Plan 27:213-221, 2012

42. Shehu BB, Ameh EA: Challenges of managing neural tube defects in sub-Saharan Africa. Ann Trop Paediatr 24:109 110,2004
43. Sheldon GF, Ricketts TC, Charles A, King J, Fraher EP, Meyer A: The global health workforce shortage: role of surgeons and other providers. Adv Surg 42:63-85, 2008

44. Shibre T, Alem A, Tekle-Haimanot R, Medhin G, Tessema A, Jacobsson L: Community attitudes towards epilepsy in a rural Ethiopian setting: a re-visit after 15 years. Ethiop Med J 46:251-259, 2008

45. Shrime MG, Bickler SW, Alkire BC, Mock C: Global burden of surgical disease: an estimation from the provider perspective. Lancet Glob Health 3 (Suppl 2):S8-S9, 2015

46. Shrime MG, Dare AJ, Alkire BC, O’Neill K, Meara JG: Catastrophic expenditure to pay for surgery worldwide: a modelling study. Lancet Glob Health 3 (Suppl 2):S38-S44, 2015

47. Siddiqi OK, Atadzhanov M, Birbeck GL, Koralnik IJ: The spectrum of neurological disorders in a Zambian tertiary care hospital. J Neurol Sci 290:1-5, 2010

48. Thaddeus S, Maine D: Too far to walk: maternal mortality in context. Soc Sci Med 38:1091-1110, 1994

49. Huber B: Uganda: After surgery, the struggle continues. Pulitzer Center. May 13, 2015. (http://pulitzercenter.org/ reporting/africa-uganda-healthcare-surgery-catheter-hydrocephalus) [Accessed December 15, 2015]

50. Voelker R: Experts say projected surgeon shortage a "looming crisis" for patient care. JAMA 302:1520-1521, 2009

51. Warf BC: Educate one to save a few. Educate a few to save many. World Neurosurg 79 (2 Suppl):S15.e15-S15.e18, 2013

52. Warf BC: Neurosurgical humanitarian aid. J Neurosurg Pediatr 4:1-3, 2009

53. Warf BC, Alkire BC, Bhai S, Hughes C, Schiff SJ, Vincent $\mathrm{JR}$, et al: Costs and benefits of neurosurgical intervention for infant hydrocephalus in sub-Saharan Africa. J Neurosurg Pediatr 8:509-521, 2011

54. Warf BC, Dagi AR, Kaaya BN, Schiff SJ: Five-year survival and outcome of treatment for postinfectious hydrocephalus in Ugandan infants. J Neurosurg Pediatr 8:502-508, 2011

55. Xu K, Evans DB, Kadama P, Nabyonga J, Ogwal PO, Nabukhonzo P, et al: Understanding the impact of eliminating user fees: utilization and catastrophic health expenditures in Uganda. Soc Sci Med 62:866-876, 2006

56. Zafar SN, Fatmi Z, Iqbal A, Channa R, Haider AH: Disparities in access to surgical care within a lower income country: an alarming inequity. World J Surg 37:1470-1477, 2013

\section{Disclosures}

The authors report no conflict of interest concerning the materials or methods used in this study or the findings specified in this paper.

\section{Author Contributions}

Conception and design: Davis, Awori, Strahle. Acquisition of data: Awori, Okechi. Analysis and interpretation of data: Davis, Awori. Drafting the article: Davis, Awori. Critically revising the article: Davis, Awori, Strahle. Reviewed submitted version of manuscript: Davis, Awori, Strahle. Approved the final version of the manuscript on behalf of all authors: Davis. Statistical analysis: Davis. Administrative/technical/material support: Strahle, Okechi. Study supervision: Strahle, Okechi.

\section{Correspondence}

Matthew C. Davis, Department of Neurosurgery, University of Alabama at Birmingham, 1064 Faculty Office Tower, 1620 6th Ave. S, Birmingham, AL 35234. email: matthewdavis@uabmc. edu. 